\title{
Järvisedimentin hyödyntämismahdollisuudet Etelä-Pohjanmaan Järviseudulla
}

\author{
Anna Saarela \\ SeAMK maa-ja metsätalouden yksikkö,Tuomarniemi, 63700 Ähtäri, anna.saarela@ seamk.fi,
}

\section{Tiivistelmä}

Energiaomavaraisuuden kasvattaminen on tärkeää aluetaloudelle ja lähellä tuotetun energian käyttö on järkevää myös ympäristövaikutusten kannalta. Uutena asiana alueen bioenergiakentällä on noussut esiin järvien eloperäisen pohjasedimentin käyttö paikallisessa energiantuotannossa, esimerkiksi polttoraakaaineen tuotannossa tai biokaasutukseen sopivana materiaalina. Samalla mahdollisuutena on alueen järvien tilan parantaminen ja niiden virkistyskäyttömahdollisuuksien lisääminen.

Vesistöjen rehevöitymisen perimmäinen syy on järven ravinnetason kasvu. Ravinteita pääsee vesiin sekä järven omasta tuotannosta että valuma-alueelta eloperäisenä humuksena sekä ravinteina. Osa järvissä tapahtuneesta rehevöitymisestä on seurausta ihmisen toiminnasta. Poistamalla vesistön pohjiin kerrostunutta eloperäistä materiaalia voitaisiin vesistöjen rehevöitymistä hillitä ja saada lisäksi kelvollista materiaalia esimerkiksi energiantuotantoon.

Esiselvityshankkeen tarkoituksena on selvittää sedimentin käyttömahdollisuuksia ja käytön mahdollisia rajoitteita (mm. raskasmetallipitoisuudet). Hankkeella tehtiin kesäkuussa sedimenttinäytteenottoa Alajärvestä sekä Ähtärin Hankavedestä. Pohjalietteen eloperäisen aineksen pitoisuus oli parhaimmillaan $35 \%$. Näytemateriaalin teholliseksi lämpöarvoksi määritettiin 13,4 MJ/kg, joka on hieman alempi kuin turpeella keskimäärin $(21 \mathrm{MJ} / \mathrm{kg})$, johtuen todennäköisesti runsaasta kivennäismaan osuudesta sedimentissä.

Raskasmetallipitoisuuksien osalta kadmiumin (Cd) ja Alajärvessä arseenin (As) pitoisuudet ylittivät Ympäristöministeriön (2004) määrittämien haitallisten aineiden pitoisuuksien raja-arvot sedimentissä. Materiaalin lannoitekäyttöön metallien pitoisuudet jäivät selvästi alle lannoitteille määriteltyjen rajaarvojen.

Ähtärin Hankavedellä 24.8.2011 kelluvan kaivinkoneen näytöstilaisuudessa tehdyn näytteenoton yhteydessä seurattiin veden näkösyvyyden muutoksia päivää ennen näytöstilaisuutta, heti näytöksen jälkeen ja edelleen kahden vuorokauden välein, kunnes veden näkösyvyys oli palannut näytteenottoa edeltävään tilaan. Lahdesta otettiin lisäksi vesinäyte, jonka perusteella näytteenoton vaikutukset olivat vähäisiä.

Hanketta hallinnoi Seinäjoen ammattikorkeakoulun maa- ja metsätalouden yksikkö. EteläPohjanmaan liitto, alueen kunnat sekä Seinäjoen ammattikorkeakoulu rahoittavat hanketta.

Asiasanat: Järvisedimentti, paikallinen bioenergian tuotanto, vesistöjen rehevöityminen 


\section{Johdanto}

\section{Bioenergian lisäämistavoitteet}

Euroopan unionin ilmasto- ja energiastrategian tavoitteiden mukaan Suomi on sitoutunut lisäämään uusiutuvan energian osuutta 28,5 \%:sta 38 \%:iin vuoteen 2020 mennessä. (Directive 2009/28/EC 2009) Tavoitteen saavuttaminen merkitsee energiatehokkuuden ja energiansäästön lisäksi voimakasta uusiutuvan energian käytön lisäämistä. Suurin lisäämistavoite kohdistuu metsäenergian tuotantoon, mutta myös mm. tuulivoiman ja biokaasun käyttöä voidaan lisätä huomattavasti. (Pekkarinen 2010) Uusiutuviin energianlähteisiin lukeutuvia biopolttoaineita saadaan metsissä, soilla ja pelloilla kasvavista biomassoista sekä yhdyskuntien, maatalouden ja teollisuuden eloperäisistä kiinteistä, nestemäisistä ja kaasumaisista jätteistä. (Saarela \& Lauhanen 2011, Lauhanen \& Laurila 2007)

\section{Vesien tila}

Järviseudun sisävedet ovat pieniä, matalia ja tästä johtuen herkkiä muutoksille. Isot järvet, kuten Lappajärvi sekä Alajärvi ovat rehevöityneet ja niissä esiintyy lähes vuosittain leväkukintoja. Alajärvi on EteläPohjanmaan ainoa järvi, joka on luokiteltu ekologisesti huonoon tilaan. Alajärvi on luonnostaan matala ja runsashumuksinen. Järven pinta-ala on 1077 ha, keskisyvyys $1,4 \mathrm{~m}$ ja suurin syvyys $7 \mathrm{~m}$. Alajärven valuma-alue on pinta-alaltaan suuri, $478 \mathrm{~km}^{2}$. Altaan valuma-alueelle tyypillistä on tehokas maankäyttö, erityisesti maa- ja metsätalous sekä turvetuotanto, jotka hajakuormittavat vesistöjä. Alajärven vedet laskevat Lappajärveen ja edelleen Ähtävänjokea pitkin Luodon-Öjanjärveen. (Alajärven kunnostushanke 2010)

Ähtärin kunnan alueella oleva Hankavesi on Väliveden kautta yhteydessä Ähtärinjärveen. HankavesiVälivesi on pinta-alaltaan 1292,8 ha ja järven suurin syvyys on $16 \mathrm{~m}$. Osavaluma-alue on pinta-alaltaan 72 $\mathrm{km}^{2}$. Valuma-alue on suurimmaksi osaksi (noin $64 \%$ ) metsämaata, peltoja alueella on noin $22 \%$. Hankavesi on luokiteltu lievästi reheväksi. Rehevöityminen alkoi 1940-luvun lopulla ja kiihtyi 1950-luvulla pellonraivauksen ja metsäojitusten seurauksena ja edelleen suurin osa järveen tulevasta kuormituksesta on hajakuormitusta. Järvi on suuren humuspitoisuuden takia ruskeavetinen ja lievästi hapan ( $\mathrm{pH} 5,7)$. (Ähtärinjärvi-projekti 2011) Hankavesi kuuluu Kokemäenjoen vesistöalueeseen.

\section{Hankkeen tavoitteet}

Esiselvityksen tavoitteena on kartoittaa Etelä-Pohjanmaan Järviseudulla järvisedimenttiin perustuvan energian tuotannon ja käytön mahdollisuuksia. Järvilietteen mahdollisuuksia paikallisessa energiantuotannossa tarkastellaan selvittämällä:

1) ovatko Alajärven ja vertailujärven pohjasedimentit kivennäismaata vai eloperäistä polttoon soveltuvaa materiaalia

2) sedimentin kemiallinen koostumus, mm. raskasmetallit, jotka voivat vapautua veteen sedimenttiä nostettaessa tai ilmaan materiaalia poltettaessa,

3) toiminnan vesistövaikutukset järven virkistyskäytön kannalta,

4) tuotannossa tarvittavat koneet kehitystarpeineen

5) sedimenttien muita käyttömahdollisuuksia

6) toiminnan lupamenettely

Hanketta hallinnoi Seinäjoen ammattikorkeakoulun maa- ja metsätalouden yksikkö ja sen toteutusaika on 15.4.2011- 29.2.2012. Etelä-Pohjanmaan liitto, alueen kunnat sekä Seinäjoen ammattikorkeakoulu rahoittavat hanketta. 


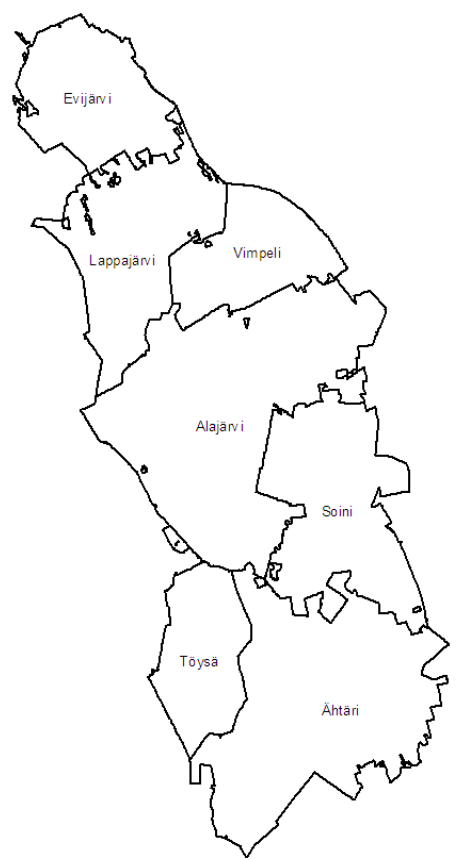

Kuva 1. Projektin toteutusalue.

\section{Aineisto ja menetelmät}

Kesäkuussa 2011 otettiin sedimenttinäytteet Alajärvestä $(n=5)$ sekä vertailunäyte Ähtärin Hankavedestä (n =1). Näytteistä määritettiin kuiva-ainepitoisuus (\%), hehkutushäviö (\% org.), pH, kokonaisfosfori (kok-P g/kgKA) sekä kokonaistyppi (Kjeldahl-N g/kgKA). Eniten orgaanista ainetta sisältäneistä näytteistä $(n=2)$ määritettiin lisäksi raskasmetallipitoisuudet.

Sedimentin käyttökelpoisuus maanparannukseen määritettiin viljavuustutkimuksella ja lämpöarvo kuiva-aineessa (MJ/kg) mitattiin Kannuksen sekä Vantaan Metsäntutkimuslaitoksen (Metla) toimipisteissä. Vesistövaikutuksia arvioitiin 24.8.11 tehdyn näytteenoton yhteydessä seuraamalla veden näkösyvyyttä sekä 29.8.11 otetulla vesinäytteellä.

\section{Tulokset ja tulosten tarkastelu}

Pohjalietteen eloperäisen aineksen pitoisuus oli Alajärvessä enimmillään $35 \%$ ja Tuomarniemenlahdella 28 \%. Kalorimetrisen lämpöarvon mittaamiseen käytettiin pommikalorimetriä (SFS-EN 14918), jolla saadaan määritettyä kemiallisen reaktion lämpömäärä sekä aineiden ominaislämpökapasiteetti. Yksinkertaistettuna laitteessa poltettava aine palaa vakiotilavuudessa ja luovuttaa palaessaan tietyn määrän energiaa lämpönä ympärillä olevaan veteen. Veden lämpötilan muutoksesta saadaan laskettua aineen lämpöarvo. Kalorimetrisesta lämpöarvosta (ns. ylempi lämpöarvo) voidaan laskennallisesti määrittää alempi lämpöarvo (ns. tehollinen lämpöarvo) sekä lämpöarvo saapumistilassa.

Sedimentin kalorimetriseksi lämpöarvoksi mitattiin 14,22 MJ/kg. Sedimenttinäytteen teholliseksi lämpöarvoksi määritettiin 13,4 MJ/kg, eli 3,7 MWh/t. Näytteen tuhkapitoisuus (SFS-EN 14775) oli 40,59 $\%$. Energiaturpeen polttokosteus on noin $40 \%$ ja tätä kosteuspitoisuutta käytettiin sedimentin polttokosteuden lämpöarvon määrittämiseksi. Sedimentin lämpöarvo $40 \%$ polttokosteudessa (saapumistilassa) on 7,06 (MJ/kg k.a) eli 1,96 MWh/t. Polttokosteuden ollessa 50 \% lämpöarvo on 5,48 (MJ/kg k.a) 1,52 MWh/t. 
Materiaalin tehollinen lämpöarvo saapumistilassa $\mathrm{Q}_{\text {net,ar }}$ laskettiin seuraavan yhtälön mukaisesti (CEN/TS 14918:2005):

Qnet, ar $=Q_{\text {net }} d \times \frac{100-\text { Mar }}{100}-0,02443 \times$ Mar

missä: $Q_{\text {net, d }} \quad$ kuiva-aineen tehollinen lämpötila $(\mathrm{MJ} / \mathrm{kg})$

$\mathrm{M}_{\mathrm{ar}} \quad$ vastaavan polttoaine-erän kokonaiskosteus saapumistilassa

painotettuna kostean polttoaineen massalla (\%)

$0,02443[\mathrm{MJ} / \mathrm{kg}]$ veden höyrystymiseen kuluva lämpömäärä vakiopaineessa $\left(+25^{\circ} \mathrm{C}\right)$

Raskasmetallipitoisuuksien osalta kadmiumin (Cd) ja Alajärvessä arseenin (As) pitoisuudet ylittivät Ympäristöministeriön (2004) määrittämien haitallisten aineiden pitoisuuksien raja-arvot sedimentissä. PIMA-arvo kuvaa Ympäristöministeriön (2007) määrittämän haitallisten aineiden raja-arvopitoisuuksia maaperässä. Lannoitekäyttöä varten metallien pitoisuudet jäivät selvästi alle lannoitteille määriteltyjen rajaarvojen. Sedimentin typpipitoisuudet olivat $1,3-16 \mathrm{~g} / \mathrm{kg}_{(\mathrm{k} . \mathrm{a} .)}$ sekä fosforipitoisuudet välillä $1-3,4 \mathrm{~g} / \mathrm{kg}_{(\mathrm{k} . \mathrm{a})}$.

Taulukko 1. Tuomarniemen ja Alajärven sedimenttien metallipitoisuudet sekä sedimentin ja maaperän haitallisten metallien raja-arvopitoisuudet. Kadmiumin (Cd) pitoisuudet Tuornarniemellä sekä Alajärvellä ylittivät sedimentin taso 1:n raja-arvon, mutta alittivat pilaantuneen maan raja-arvon (PIMA). Alajärven arseenipitoisuus ylitti sekä sedimentin taso 1:n raja-arvon että pilaantuneen maan raja-arvon.

\begin{tabular}{|l|c|c|c|c|}
\hline & Tuomarniemi & $\begin{array}{c}\text { Alajärvi } \\
4 \\
\mathrm{mg} / \mathrm{kg} \\
\mathrm{k} . \mathrm{a}\end{array}$ & $\begin{array}{c}\text { Taso } 1 \\
\mathrm{mg} / \mathrm{kg} \\
\mathrm{k} . \mathrm{a} .\end{array}$ & PIMA \\
$\mathrm{mg} / \mathrm{kg}$
\end{tabular}

Maanparannusarvon määrittämiseksi Tuomarniemenlahden näytteestä tilattiin viljavuusanalyysi Suomen ympäristöpalvelu Oy:stä. Maalaji määritettiin eloperäiseksi multamaaksi. Näytteen happamuus oli tasolla hyvä, pH 5,9. Ravinteiden osalta magnesiumin (Mg) pitoisuus oli hyvä, $250 \mathrm{mg} / \mathrm{l}$, rikin tyydyttävä, $13 \mathrm{mg} / \mathrm{l}$ ja kalsiumin (Ca) tyydyttävä, $1530 \mathrm{mg} / \mathrm{l}$. Pääravinteiden fosforin (P) ja kaliumin pitoisuudet jäivät huonolle tasolle. Fosforia näytteessä oli < 1,5 mg/l ja kaliumia 34 mg/l.

Tuomarniemenlahden veden näkösyvyyttä mitattiin päivää ennen kaivinkoneen työnäytöstä, heti näytöksen jälkeen ja kahden vuorokauden välein, kunnes näkösyvyys oli palannut näytteenottoa edeltävään tilaan. Vedenlaatu määritettiin vesinäytteellä viisi päivää näytöksen jälkeen 29.8.11. 


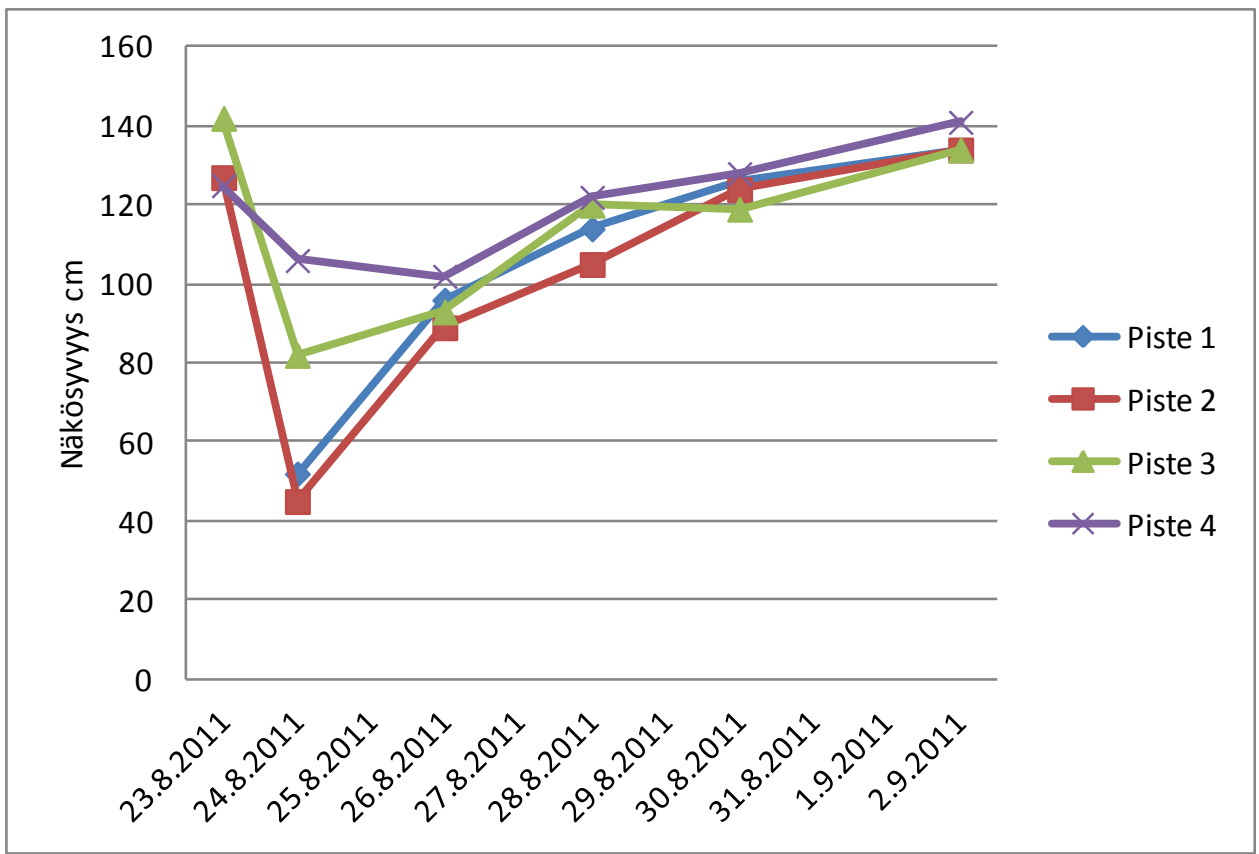

Kuva 2. Tuomarniemenlahden näkösyvyyden seuranta 23.8.- 2.9.2011. Näytteenotto tehtiin 24.8.2011.

Materiaalin soveltuvuutta biokaasutukseen tarkasteltiin kirjallisuuden sekä asiantuntija-arvioiden (Luostarinen 2011) perusteella. Sedimentin suuri kivennäisaineen määrä ja toisaalta pieni bakteerien toiminnalle välttämättömän eloperäisen aineksen määä hidastaa biokaasuprosessia. Kaasutuksessa epäorgaanisen materiaalin osuuden tulisi jäädä alle $35 \%$ :n, jotta biokaasun saanto olisi kannattavalla tasolla.

Järvisedimentti sopisi käytettäväksi hyvin rantapeltojen maanparannusaineena. Rantapellot ovat helposti vettyviä ja kasvukauden kuivavara on turhan pieni. Kuivavaraa kasvattamalla kasvit pystyvät hyödyntämään maaperän ja sedimentin ravinteita tehokkaammin ja kasvien tehokas ravinteiden hyödyntäminen vähentää myös vesistöön huuhtoutuvaa ravinnekuormaa. Ennen pellolle levittämistä sedimentin koostumus tulisi selvittää raskasmetallien ja viljavuusominaisuuksien osalta. Järvisedimentti on usein hapanta, joten peltojen kalkitsemisesta tulee huolehtia ruoppausmassan levityksen yhteydessä

\section{Johtopäätökset}

Sedimentin energiakäyttö on mahdollista tietyin rajoittein. Poltettavan materiaalin kivennäisainepitoisuuden tulisi olla riittävän pieni, jolloin lämpöarvo on korkeampi ja syntyvän tuhkan määrä pienempi. Polttokattilatekniikalle sedimentin ominaisuudet aiheuttavat joitain rajoituksia; parhaiten polttoon sopinee raaka-ainevalikoiman ja poltettavan materiaalin kosteuden suhteen joustava leijukerroskattila (leijupetikattila). Myös savukaasujen puhdistustekniikan tulisi sedimentin poltossa olla tehokasta.

Sedimentin soveltuvuutta biokaasutukseen heikentää sen suuri epäorgaanisen aineksen osuus. Kivennäismaan määrän tulisi olla mieluiten alle $35 \%$, jotta biokaasun muodostus tehostuisi. Maanparannusaineeksi järvisedimentti soveltuu, jos sen haitta-ainepitoisuus jää riittävän pieneksi. Sedimentti on typpi- ja fosforiköyhää, joten materiaalilla saadaan lähinnä lisättyä maan humuspitoisuutta. 


\section{Kirjallisuus}

Alajärven kunnostushanke 2010. [Verkkojulkaisu]. Etelä-Pohjanmaan ELY-keskus. [Viitattu 13.6.2011]. Saatavana: http://www.elykeskus.fi/fi/ELYkeskukset/EtelaPohjanmaanELY/Tehtavatjatoiminta/projektit_ja_hankkeet/Sivut/Alajarvenkunnostus hanke.aspx

CEN/TS 14918:2005. Solid Biofuels - Method for determination of calorific value.

Directive 2009/28/EC of the European Parliament and of the Council of 23 April 2009 on the promotion of the use of energy from renewable sources and amending and subsequently repealing Directives 2001/77/EC and 2003/30/EC.

Lauhanen, R. \& Laurila, J. 2007. Bioenergian hankintalogistiikka. Tapaustutkimuksia Etelä-Pohjanmaalta. Seinäjoen ammattikorkeakoulun julkaisusarja B. Raportteja ja selvityksiä 33. $138 \mathrm{~s}$.

Luostarinen J. 2011. Sedimentin sopivuus biokaasutukseen. Suull. tiedonanto.

Pekkarinen M. 20.4.2010. Kohti vähäpäästöistä Suomea. Uusiutuvan energian velvoitepaketti. [Ppt-esitys]. TEM tiedotteet 2010 [Viitattu 3.3.2011]. Saatavana: http://www.tem.fi/index.phtml?101881_m=98836\&s=4265

Saarela, A. \& Lauhanen R. 2011. Bioenergiapotentiaalit. Alajärvi, Evijärvi, Lappajärvi, Soini, Töysä, Vimpeli ja Ähtäri. [Verkkojulkaisu]. Seinäjoen ammattikorkeakoulu. [Viitattu 22.11.2011]. Saatavana: http://www.seamk.fi/loader.aspx?id=c0526a7d-4b9f-46f8-b343-3c51ab2f542d

Ähtärinjärvi-projekti (ei päiväystä). [Verkkojulkaisu]. Ähtärin kaupunki. [Viitattu 22.11.2011]. Saatavana: http://www.ahtari.fi/Default.aspx?id=445748 